\title{
BANCO DE DADOS, CONHECIMENTO E REDES CIENTÍFICAS: A VISIBILIDADE NA SOCIEDADE DA INFORMAÇÃO
}

Maria Cristina Cereser Pezzella

Professora do Programa de Pesquisa e Extensão e Pós-graduação em Direito pela UNOESC. Coordenadora/Líder de Grupo de Pesquisa (CNPq) intitulado Direitos Fundamentais Civis: A ampliação dos Direitos Subjetivos - sediado na UNOESC. Graduada em Direito pela Pontifica Universidade Católica do Rio Grande do Sul PUCRS (1988). Mestre em Direito pela Universidade Federal do Rio Grande do Sul - UFRGS (1998). Doutora em Direito pela Universidade Federal do Paraná - UFPR (2002). Avaliadora do INEP/MEC.

Thaís Janaina Wenczenovicz

Docente adjunta na Universidade Estadual do Rio Grande do Sul (UERGS). Professora colaboradora do Programa de Pesquisa e Extensão e Pós-Graduação em Direito da Universidade do Oeste de Santa Catarina (UNOESC).

\section{Resumo}

O devido estudo tem por objetivo analisar a proteção de dados pessoais fornecidos voluntariamente pelas pessoas e coletados em arquivos sem o seu consentimento, e em afronta aos seus direitos de sigilo, segredo e privacidade afetando o direito de personalidade, além de deixar de concretizar o direito à privacidade junto a Sociedade da Informação. A Sociedade da Informação, lastreada no primado do conhecimento, na criação, circulação e oneração da informação, consubstancia-se na atual forma de fomento das interrelaçóes pessoais, e no direcionamento dos aspectos econômicos, políticos, jurídicos e sociais, provocando alteraçóes significativas no cotidiano. Com efeito, na Sociedade da Informação a pessoa é primeiramente representada por informaçôes, ou seja, conhecida por dados, números, rotinas de compras e gastos, na forma de textos, imagens, sons e dados registrados. Esta nova percepção do indivíduo, como um ser informacional, passa a reclamar a proteção da privacidade, notadamente por se tratar de um direito fundamental de primeira grandeza, reconhecido como direito de personalidade, com caracteres de indisponibilidade, intransmissibilidade, inalienabilidade e imprescritibilidade. A pesquisa utilizada foi preponderantemente bibliográfica, com recurso à doutrina nacional e internacional ponderando os diversos ramos da ciência jurídica, além da perspectiva histórica - fundamental a melhor compreensão da complexidade no contexto contemporâneo. 


\section{Palavras-chave}

Banco de Dados; Conhecimento; Sociedade da Informação.

\section{Abstract}

The present study aims to analyze the protection provided personal data, voluntarely given by people and collected in files without their consent, an affront to their confidentiality, confidentiality and privacy rights, affecting the right of personality, also fail to materialize the right to privacy in the Information Society. The Information Society, backed the rule of knowledge, creation, circulation and encumbrance information, is embodied in the current form of promotion of personal interrelationships, and the targeting of economic, political, legal and social, causing significant changes in daily life. Indeed, in the information society, the person is primarily represented by information, therefore known for data, numbers, shopping routines and spending, in the form of text, images, sounds and recorded data. This new perception of the individual, as an informational being, shall claim the protection of privacy, especially because it is a fundamental right of first magnitude, recognized as personality right, unavailability of characters, intransferable, inalienable and imprescriptible. The research was mainly based literature, using the national and international doctrine pondering the various branches of legal science, beyond the historical perspective - key to better understanding the complexity in the contemporary context.

\section{Key words}

Database; Knowledge; Information Society.

\section{Introdução}

A Sociedade da Informação faz parte do cotidiano de grande parte dos indivíduos, seja por meio de aparelhos eletrônicos como televisóes, celulares, computadores, e principalmente pelo uso a Internet. $\mathrm{O}$ ambiente virtual só foi passível de ser vivenciado após o surgimento da Sociedade da Informação, a qual desencadeou a dicotomia entre o real e o imaginário.

O objetivo do presente artigo consiste na análise da proteção de dados pessoais fornecidos voluntariamente pelas pessoas e coletados em arquivos sem o seu consentimento, e em afronta aos seus direitos de sigilo, segredo e privacidade afetando o direito de personalidade, além de deixar de concretizar o direito à privacidade.

A investigação envolve a formação dos bancos de dados com informaçóes prestadas voluntariamente pelo próprio titular que ao desconhecer qual a destinação conferida aos 
dados entregues de boa-fé os oferece sem resistência, e sem a dimensão de qual será a utilização conferida aos mesmos.

Verifica-se que os dados podem ser coletados com uma finalidade e utilizados com fins diversos aos que foram informados. No cotidiano as pessoas tomam atitudes desavisadas e prestam informaçóes a seu respeito no ato de abrir contas bancárias, doar sangue, fazer a habilitaçáo para carteira de motorista, renovar o título eleitoral ou em qualquer outra hipótese fornecem informaçóes pessoais que podem circular sem o seu conhecimento e contra a sua vontade para fim diverso do imaginado.

Este artigo também é resultado da pesquisa desenvolvida ao longo dos últimos cinco anos por um grupo de pesquisa que envolve professores doutores, mestrandos e doutorandos agregando esforços de várias IES (Instituições de Ensino Superior) Graduação e incluindo vários programas de pós em diversos Estados da federação brasileira e objetiva identificar as novas formas em que a Sociedade da Informação cria vínculos e faz circular informações. ${ }^{1}$

As novas técnicas são potentes e póe em risco as liberdades pessoais, pois o emaranhado tecnológico pode devassar e expor a esfera mais íntima da pessoa e causar danos a sua imagem e aos direitos de personalidade.

A Sociedade da Informação se caracteriza pela velocidade na transmissão da informação e na elasticidade do horizonte do dano que pode ocorrer e ganhar repercussão infinitamente superior ao que se conhecia no passado.

Os novos veículos de comunicação e difusão podem macular os direitos de personalidade em proporçôes enormes e simultaneamente uma informação pode ser recebida em todos os recantos do planeta causando danos irreparáveis.

Por esta razão o direito ao segredo e ao sigilo dos dados consiste num bem de valor imensurável que merece o esforço das estruturas do saber inclusive da ciência jurídica para bem proteger e reprimir seu uso indevido dos dados pessoais.

Nesta perspectiva a pesquisa aqui desenvolvida a quatro mãos também tem o objetivo de aferir e compreender a atual moldura da privacidade, da intimidade, do recato, do sossego na perspectiva dos julgados dos tribunais brasileiros tanto nos ciberespaços, quanto nos espaços públicos e privados, como também aferir como o direito internacional se posiciona a respeito da proteção aos direitos de personalidade.

1 O resultado dos estudos apontados foram apresentados e publicados junto ao XXIII Congresso Nacional do CONPEDI/UFPB - João Pessoa/PB; no I Encontro de Internacionalizaçăo do CONPEDI/ Barcelona-Espanha; no XXIII Encontro Nacional do CONPEDI/UFSC - Florianópolis/SC; Autumn 2014 - Unoesc International Legal Seminar - Brazil - Germany, Chapecó/SC e está inserido no Grupo de Pesquisa Direitos Fundamentais Civis: a ampliação dos direitos subjetivos no Programa de Pós-Graduação em Direito da Unoesc - Campus Chapecó/Brasil. 
Em virtude da Sociedade da Informação caracterizar-se pela criação, a difusão e a circulação da informação e atuar também de forma direta na transformação das relaçôes pessoais se verifica profundas mudanças no cotidiano que são sentidas pelo direito econômico que cria novos bens e novos valores materiais e imateriais. Os processos desencadeados alteram o cotidiano vivido pela pessoa humana nas perspectivas: físicas, morais e espirituais.

As tecnologias disponíveis na Sociedade da Informação permitem a captação da presença humana nos mais variados espaços e ambientes que transite fisicamente ou naqueles em que faz circular informaçóes a seu respeito, e, por conseguinte, a conservação destas vivências captadas, com imediata ou posterior reprodução e exposição a um infindável contingente de pessoas unidas apenas por laços tecnológicos, podendo estar espacialmente distantes.

A combinação de tecnologias de informação e comunicação pode captar via informaçóes pessoais, e via objetos à presença humana em ambientes variados. Verifica-se a elevada visibilidade e exposição do ser humano.

Este fenômeno desperta preocupação em torno dos direitos à privacidade, e também as possibilidades de encontrar mecanismos jurídicos para sua proteção, reconhecida a natureza de direito fundamental aos direitos à privacidade.

A presente proposta tem por objeto secundário a proteção da privacidade diante da visibilidade humana perpetrada na Sociedade da Informação, enfrentando a dificuldade de se conferir efetividade à privacidade em uma conjuntura marcada pela rapidez da integração e invasão dos meios tecnológicos na vida cotidiana, bem como em outros estudos mais aprofundados pretende em rede refletir a respeito dos marcos legislativos existentes e os em projeto de implementação, inclusive do meditar a respeito da criação jurisprudencial, além do exercício de cotejar as experiências similares ocorridas fora do Brasil.

$\mathrm{O}$ objetivo geral consiste em examinar as conotaçóes que assume o direito à privacidade na Sociedade da Informação ante o fenômeno da visibilidade e encontrar formas de proteção aos direitos fundamentais violados ou ameaçados de violação. Acrescido a esse objetivo também se dispóem a compreender as especificidades da Sociedade da Informação, perpassando pela transformação ocasionada no cotidiano, assim com a influência e as consequências desta nova forma de viver e conviver;

A pesquisa cogita duas hipóteses de investigação, que são: A primeira consiste em perceber as transformaçóes e o modo de ser na Sociedade da Informação. Percebe-se novos padrôes de consumo, novas formas de armazenar informaçôes, novas formas de circular mercadoria e dados pessoais em contraposição a fragilidade na proteção dos direitos de personalidade. A massificação das relações de consumo e a oferta de novos veículos de informação causam a superexposição e a coleta de informaçóes fornecidas voluntariamente pelos consumidores, mas sem que eles autorizem a comercialização de seus dados. 
A segunda hipótese se apresenta como a possibilidade de, mesmo diante das novas conformaçóes sociais e comportamentais da Sociedade da Informação, defender a validade do direito à privacidade no seu sentido clássico, como o direito de estar só, direito ao segrego, ao recato, e então possibilitar a edificação de novas ferramentas jurídicas aptas a impedir qualquer acesso alheio ao universo privativo da vida humana.

O presente estudo construiu-se a partir do método dedutivo, iniciando pelo traçado das linhas gerais em torno da Sociedade da Informação, perpassando pelo exame do direito à privacidade, alocando-o na categoria dos direitos fundamentais, sob o olhar atento dos pressupostos do Direito Econômico para desvelar as formas de proteção existentes captando suas possibilidades e fragilidades.

\section{Sobre a Sociedade da Informação}

Sociedade da Informação é uma terminologia que surgiu no fim do Século XX e teve sua origem e desenvolvimento com o movimento de globalização. Esse conceito ainda não está consolidado, uma vez que se encontra em processo de formação e expansão considerando sua complexidade nos meios de produção e rapidez evolutiva. Para o âmbito Nacional e Internacional, a Sociedade da Informação é considerada como uma nova "Era", onde a tecnologia permite por meio da transmissáo de dados, de baixo custo, utilizar de informaçóes rápidas e velozes a troca e compartilhamento de informaçóes, em quantidades antes inimagináveis, assumindo valores políticos, religiosos, sociais, antropológicos, econômicos e fundamentais. ${ }^{2}$

Percebe-se que a Sociedade da Informação é apenas uma consequência da exploração informacional caracterizada pela aceleração dos processos de produção e de disseminação das informaçóes e de conhecimento. Essa aceleração é ditada pelos elevados números de atividades produtivas que dependem da gestão de fluxos informacionais, aliado ao uso constante das novas tecnologias de informação e comunicação.

A Sociedade da Informação é caracterizada pela criação, circulação da informação em tempo real e simultaneamente para todo o planeta não havendo limites para chegar

2 Segundo Mattelart (2009), no final de 1989, surgiu nos EUA o primeiro provedor de acesso à Internet por ligação telefônica,"The World". Em outubro de 1990 a "Clari-Net" ofereceu o primeiro recurso comercial na Internet. Em 22 de maio de 1990 a Microsoft lançou o Windows 3.0, para ser usado em microcomputadores que tinham instalado o sistema operacional MS-DOS. Era suportado pelo processador 386, podendo ser multitarefa com programas DOS e também com programas Windows. Com memória virtual e proteção, a versão 3.0 transformou os pcs em máquinas multifuncionais. Já a interface com o usuário foi projetada para se parecer com o "Presentation Manager": tinha um gerenciador de programas baseado em ícones e um gerenciador de arquivos em estilo árvore. Gráficos em 16 cores tornaram possível a entrega de ícones renovados. Imediatamente após o lançamento do Windows 3.0, começaram a aparecer programas para funcionar nesse ambiente, da própria Microsoft e, também, de muitos desenvolvedores. 
ao conhecimento de todos e esta nova via de comunicação altera as relaçóes pessoais causando mudanças nas relaçóes econômicas, políticas e jurídicas afetando o cotidiano de maneira sem precedentes.

Toffler (1998, passim) refere-se à Sociedade da Informação como um estado onde coexistiriam dois relógios, um analógico e outro digital. $\mathrm{O}$ analógico a regular a vida humana presa a limites temporais e físicos, e o digital transcenderia estes limites exigindo acesso e açóes simultâneas em torno e em razão da informação, como se presente um tempo e um espaço paralelos.

$\mathrm{Na}$ Sociedade da Informação a pessoa é apreendida como um ser informacional, de tal forma que o ser humano consubstancia-se na informação daquilo que dele se faz. Tanto quanto as relaçóes sociais pressupóem a informação para se moldarem, os indivíduos, na Sociedade da Informação, se organizam a partir daquilo que são em virtude das informações sobre sua condição humana e social.

E não há o que se falar propriamente em "impacto" das novas tecnologias da informação sobre a sociedade, porque se assim ocorresse o ambiente social deveria ser tomado como um recipiente vazio, não reativo, despido de dinamicidade, e que apenas suportasse as punções projetadas pelas tecnologias. Pierre Lévy refere (2003, p. 21), "não somente as técnicas são imaginadas, fabricadas e reintegradas durante seu uso pelos homens, como também é o próprio uso intensivo de ferramentas que constitui a humanidade como tal (junto com a linguagem e as instituiçôes sociais complexas)”.

O comportamento apresentado pela Sociedade da Informação ante o contato por novas tecnologias não se mostra como um revide, refulgindo como um reflexo já comprometido pela integração daquelas tecnologias. Sabe-se que na Sociedade da Informação a tecnologia implantada ganha existência própria e irradia influxos ao corpo social, tornando impossível regredir ao estágio anterior, diante das ramificaçóes e interdependências que estendeu com a nova tecnologia integrada.

A Sociedade da Informação, ou sociedade informacional como prefere Castells (2003, p. 57-60), apresenta características específicas que permitem sua identificação e percepção como formação autônoma. A primeira destas facetas é a de que a informação é sua matéria prima, posto que as tecnologias propiciam o uso da informação pelo ser humano.

Outra característica está na profícua e elevada penetrabilidade, visto que a informação é elemento indissociável de toda ação humana, também a Sociedade da Informação é caracterizada por sua flexibilidade, já que torna facilitada a reorganização, e a factível capacidade de redefinição e ressignificação.

A interação de tecnologias é outra característica da Sociedade da Informação, pois se observa o contínuo processo de diálogo entre áreas do conhecimento e tecnologias, com integração de elementos de eletrônica, telecomunicaçôes, biologia e robótica. 
A título de exemplo, pode-se citar o impulso gerado com a possibilidade de publicar eletronicamente o conhecimento científico que resultaram em uma série de iniciativas em todo o mundo. Tendo como exemplo de ilustração, no Brasil, a criação do Portal SciElo - Scientific Electronic Library Online (http://www.scielo.br), surgiu como resultado de um projeto de pesquisa da Fundação de Amparo à Pesquisa do Estado de São Paulo (Fapesp), em parceria com o BIREME (Centro Latino-Americano e do Caribe de Informação em Ciências da Saúde) a OPAS (Organização Panamericana da Saúde) e a OMS (Organização Mundial da Saúde), cuja metodologia para publicar, garantir a preservação e prover livre acesso ao texto completo dos periódicos foi estendida posteriormente para outros países da América Latina, como Chile (http://www.scielo.cl/), México (http://scielomx.bvs. br/scielo.php), Cuba (http://scielo.sld.cu/scielo.php) e Venezuela por meio do endereço (http://www.scielo.org.ve/scielo.php).

Além disso, a Biblioteca Digital Brasileira tem sido outro meio de divulgação das informações científicas, sendo um projeto do IBICT (Instituto Brasileiro de Informação e Ciência e Tecnologia) que visa tornar visível a produção científica do país e facilitar a transferência de informaçóes científicas e tecnológicas no meio acadêmico e profissional (Marcondes \& Sayao, 2002; Neves, 2004). ${ }^{3}$

Por outro lado, tem-se a característica da lógica de redes, o aparato essencial que permite a produção, compartilhamento e disseminação da informação, e ao mesmo tempo, no despertar de tecnologias para o trato e uso da informação. Essa conformação é reconhecida na Diretiva 2002/58 da Comunidade Europeia:

O desenvolvimento da sociedade da informação caracteriza-se pela introdução de novos serviços de comunicaçóes electrónicas. $\mathrm{O}$ acesso a redes móveis digitais está disponível a custos razoáveis para um vasto público. Essas redes digitais têm grandes capacidades e possibilidades de tratamento de dados pessoais.

Diante das características acima apontadas a Sociedade da Informação desconhece, a priori, limitações espaciais e temporais, negligenciando espaços públicos e privados, conferindo-se a si próprio cunho universal e incombatível.

Citando novamente um exemplo brasileiro, é possível apontar que para democratizar o acesso à produção científica e subsidiar a pesquisa brasileira, a Capes (Coordenação de

3 Nos últimos anos, o Brasil conquistou importantes avanços na ciência e tecnologia, ocupando atualmente a $17^{\mathrm{a}}$ posição no ranking mundial de produção de novos conhecimentos científicos, pouco distante de países como Japão, Alemanha, Inglaterra e França. Por meio da Coordenação de Aperfeiçoamento de Pessoal de Nível Superior (Capes), o MEC investe na formação de recursos humanos no país e no exterior, na cooperação acadêmica internacional, na avaliação da pós-graduação brasileira (mestrado e doutorado) e no acesso e divulgação da produção científica nacional e internacional (Haddad, 2005). 
aperfeiçoamento de pessoal de nível Superior) também disponibiliza o portal de periódicos, um dos maiores bancos de informaçóes científicas do mundo e o maior da América Latina. $\mathrm{O}$ portal da Capes foi criado para universalizar o acesso à informaçáo no meio acadêmico-científico e atende a cientistas, pesquisadores, professores e estudantes.

Para tanto, sabe-se que a comunicação científica está envolvida tanto nas atividades de produção quanto de disseminação e uso da informação, em um processo que se inicia na concepção de uma ideia/projeto a ser pesquisada até o momento em que os resultados dessa pesquisa sejam aceitos pela comunidade científica. Assim, no processo da comunicação científica podem ser considerados grandes momentos: o da produção e o da divulgação do conhecimento, ${ }^{4}$ que envolvem um ou vários canais de comunicação entre os pesquisadores. Desde o início da pesquisa até o momento da divulgação dos resultados, tradicionalmente são utilizados os chamados canais informais e formais Garvey (1979).

Segundo Targino (2000), a comunicação cientifica informal é aquela que utiliza canais informais, em que a transferência da informação ocorre através de contatos interpessoais e de quaisquer recursos destituídos de formalismo, como reunióes científicas, participação em associaçóes profissionais e colégios invisíveis. Já a comunicação científica formal ocorre pela escrita veiculada em anais, periódicos, livros, relatórios técnicos, entre outros recursos. Para além disso, passa pela avaliação de instâncias superiores, o que confere credibilidade às informaçóes, por esses motivos, o papel da comunicação científica formal é "persuadir e convencer a comunidade científica e a sociedade como um todo de que os resultados entâo divulgados devem ser aceitos como conhecimento válido e consolidado.”

\subsection{Banco de Dados: Reflexões Iniciais}

Além das PIIs (Informaçôes Pessoais Identificáveis) coletadas diretamente da Internet, existem aquelas encontradas anteriormente somente em bases de dados proprietárias, ou seja, no sistema interno de agências governamentais, empresas comerciais, consultórios médicos, dentre outras, que agora estão passando para o domínio público na Grande Rede.

Devido o elevado número de aplicaçóes decorrentes dessa 'onlinização' dos bancos de dados proprietários, pode-se citar algumas delas para melhor compreensão do tema:

- os históricos dos alunos disponíveis nos sites das respectivas escolas e universidades;

- os dados relativos ao FGTS;

4 O PubMed adiciona uma média de mais de dois resumos por minuto em sua base de dados e isso apenas em ciências médicas e da vida. 
- agências governamentais detêm informaçóes de todos os cidadãos que podem ser acessadas por qualquer um, legal ou ilegalmente;

- a SERASA aponta o pretenso devedor em mora;

- os bancos de dados do judiciário trazem quem já tenha demandado em Juízo;

- os departamentos de trânsito dão informações sobre os veículos, multas e infraçóes;

- no site da Receita Federal, da posse do CPF de qualquer contribuinte, pode-se fazer uma devassa em sua vida fiscal.

Em síntese, a coleta de dados pode se dar via formulários, de forma explícita, ou implicitamente por intermédio dos cookies5; licitamente consultando bancos de dados, antes fechados, agora abertos e disponíveis livremente na rede mundial, ou utilizando-se de métodos ilícitos, como o caso dos crackers $^{6}$ invasores de sistemas de bancos de dados fechados ou protegidos.

Com o uso constante da rede, agregadas as informações coletadas é possível identificar qual o navegador utilizado, o sistema operacional, os horários, a quantidade de acessos, as áreas de preferência, bem como o número do IP (Internet Protocol), que está para a Internet assim como a impressão digital está para a identificação de pessoas. Através desse número pode-se conhecer o provedor, o navegador, o sistema operacional e, inclusive, a localização de qualquer um que tenha acessado a Internet reforçando a ideia de controle total dos indivíduos quando estão conectados.

\section{Comunicação, Informação e Privacidade}

Edifica-se a pesquisa no cenário referido, considerando que as tecnologias de informação, informática e comunicação, cada vez mais rápidas e vorazes, mais acessíveis e integralizadas aos afazeres cotidianos da vida comum, criam um ambiente em que cada indivíduo é ao mesmo tempo vigilante e vigiado de todos e por todos. Dito de outra

5 Ao contrário dos formulários, que são explícitos coletores de informaçóes pessoais, os cookies (biscoitos, em inglês) operam usualmente sem o consentimento ou o conhecimento do usuário. Cookies são pequenos arquivos de informaçóes lançados pelos sites visitados, dentro do computador do visitante, e ficam armazenados no respectivo disco rígido, para enquanto houver navegação na web, serem utilizados pela memória RAM. Existem dois tipos de cookies: os que são gravados diretamente no computador dos usuários, e servem para facilitar o carregamento do site numa posterior navegaçáo, e os que se servem apenas para coletar dados dos visitantes, cujo destino é, inevitavelmente, o banco de dados do site visitado. A coleta de PIIs, através dos cookies tem como principal objetivo - pelo menos é o que alegam os donos dos 'biscoitos' - personalizar o acesso do internauta ao respectivo site.

6 Segundo Mattelart (2009), o indivíduo categorizado como cracker tem por objetivo a obtenção de benefícios particulares ou o intenção de causar danos a terceiros. 
forma, qualquer pessoa que esteja dotado de um dispositivo tecnológico capaz de captar a presença de outros, pode registrar e reproduzi-la de forma instantânea para um contingente indeterminado de pessoas.

Captar a presença humana e realizar a sua reprodução pelos diversos ambientes da Sociedade da Informação pode efetivar-se por imagens, sons e dados pessoais, tendendo a indicar para a agressão aos direito à privacidade.

A partir da constatação que na Sociedade da Informação a inclusão e participação do indivíduo faz-se necessariamente a partir da cessão de informações a seu respeito, quer no trato com órgãos governamentais, agências de fomento, serviços educacionais, de saúde e securitários, e, com maior frequência, quer nas relações de consumo, reascende a preocupação com o direito à privacidade.

Na perspectiva tradicional a privacidade é reconhecida como do direito de ser deixado só, mas estudos atuais têm levado a se reconhecer uma nova concepção, como quando em foco as informaçóes pessoais. Doneda (2000, p. 120) defende "uma transformação na definição do direito à privacidade, do 'direito de ser deixado em paz' para o 'direito a controlar o uso que outros fazem das informaçóes que me digam respeito”.

Se utilizarmos como parâmetro os dados fornecidos pelos pesquisadores brasileiros especialmente os que atuam no Ensino Superior e Programas de Pós-Graduaçáo - quando buscam recursos financeiros para colocarem seus projetos em execução é rapidamente perceptível o 'fornecimento voluntário' de seus dados pessoais. Esses dados se constituem desde números de documentos civis até endereço residencial.

Observando índices apontados na revista Nature (2014) que traz um panorama sobre a ciência sul-americana, constata-se que o Brasil contou com 40.306 publicações em 2013 , sendo $62 \%$ desses com algum aporte de recursos públicos aos quais implicou o pesquisador ou a rede cadastrarem-se nas plataformas de fomentos deixando todos seus dados pessoais, acrescidos dos profissionais à disposiçáo do 'sistema. Inúmeros são os espaços que se anunciam e denunciam a publicização desses dados a outros órgãos e não os que foram cadastrados.

O site "Nomes Brasil"7 que permite buscar o nome e o CPF e as situaçôes cadastrais dos cidadãos gerou preocupação e polêmica em diversos meios sociais no Brasil. Em curto espaço de existência o devido site ${ }^{8}$ - deixou a comprovação da facilidade a qual os dados

7 Outras páginas na internet que oferecem serviços semelhantes ao exemplo citado, como a "Fonedados" também tiveram seus serviços cancelados pela ação da Justiça brasileira.

8 O Ministério da Justiça notificou em 06/05/2015 o provedor de acesso do site "Nomes do Brasil", através do diretor do Departamento de Proteção e Defesa do Consumidor, Amaury Oliva. O alvo da notificação é o servidor GoDaddy, que oferece a gestão de domínios na internet de modo a manter seus administradores anônimos. Por isso, não é possível consultar quem são os donos do site, criado em 
podem ser divulgados, confirmando o legado da não proteção a maioria dos usuários da rede mundial. Através desse caso citado, pode-se presumir que a página viola em primeira instância a legislação por não dar aos consumidores o direito de consentir sobre a inclusão de suas informaçóes em um banco de dados e, em segundo momento porque deixava de informar canais de contato (telefone, e-mail e endereço) para consumidores que se sentiram lesados pelo site para que pudessem contatar os responsáveis. ${ }^{9}$

Alerta no mesmo sentido Rodotà (2008, p. 24) que em um momento histórico os dados pessoais são facilmente circuláveis, a privacidade desloca-se da clássica fórmula do direito de estar só (de ser deixado em paz) para o direito de o próprio indivíduo controlar o uso e destinação das informações a seu respeito.

Visto de outra forma, a defesa da privacidade, direito a permitir recato, isolamento e solidão, acaba contrastando por vezes com uma das liberdades mais substanciais das democracias, qual seja a liberdade de expressão, referida por Meyer-Pflup (2009, p. 42), como "intrínseca à natureza do homem expor suas ideias, opiniōes, pensamentos, sensaçóes e sentimentos e tentar convencer os demais sobre a importância e veracidade deles".

A liberdade de expressão encontrou na Sociedade da Informação seu campo mais profícuo, diante da visibilidade permitida por esta, razão pela qual as limitaçóes a seu exercício justificadas pela proteção à privacidade podem soar, num primeiro momento, como atitudes antidemocráticas e autoritárias, pois de acordo com o pensamento de Farias (2008, p. 143), a liberdade de exteriorizar pensamentos, opiniōes, criaçóes, entre outras, é uma características das sociedades democráticas, servindo de "termômetro do regime democrático", ou seja, quando mais se garante a liberdade de expressão, mais democrática será a sociedade e seu sistema jurídico, pois representará menor tentativa de intromissão estatal no âmago dos indivíduos.

Nessa perspectiva, o direito à informação oferece relevantes elementos ao embate entre privacidade e liberdade de expressão, assim como para a captação, armazenamento e utilização de dados pessoais ao lado do controle que o titular possa exercer sobre estas informaçôes. O direito à informação desdobra-se nos direitos de informar, informar-se e ser informado (FARIAS, 2004, p. 162-163).

$\mathrm{O}$ primeiro consistente do direito de produzir e levar informaçóes às pessoas, o segundo no direito de buscar informações (acesso à informação, e o terceiro no direito de receber informaçóes. A questão consiste em encontrar qual a necessidade e utilidade

fevereiro de 2015. A pasta vai pedir que a empresa informe quem são os responsáveis pelo site. A página era alimentada frequentemente, segundo observação dos usuários.

9 Essa exigência foi determinada pelo decreto presidencial no 7.962 , que entrou em vigor para incluir os serviços na internet entre as diretrizes do CDC. Já o Marco Civil da Internet é violado, porque o site não cumpre a exigência de proteção adicional aos dados pessoais dos cidadãos. 
de determinada informação a respeito de uma pessoa ou de sua vida, para a vida de outras pessoas ou de uma coletividade, e como estas justificativas atuam sobre a garantia da liberdade de expressão e a proteção à privacidade. Segundo Mendes e Branco (2011, p. 320-321), "verifica-se a tendência de tomar como justificável a intrusão sobre a vida privada de alguém quando houver relevância pública na notícia que expóe o indivíduo”.

$\mathrm{O}$ direito a privacidade ${ }^{10}$ merece o reconhecimento de duas dimensóes, uma mais profunda voltada a seu caráter clássico atinente ao direito que o indivíduo tem de oporse à coleta de dados pessoais (informaçóes, imagens, sons, por exemplo) que lhe dizem respeito, e outra dimensão concernente ao direito de saber quais informaçóes se tem a seu respeito e de controlar o uso que delas pode ser feito.

A admissão dessa dupla dimensão permite buscar a eficácia material do direito fundamental e traçar discussóes sobre problemas como a privacidade de pessoas quer tenham notoriedade ou náo, bem como a possibilidade da coleta e armazenamento de dados pessoais e seu compartilhamento, o cruzamento de dados pessoais existentes em bancos de dados distintos, a formação de perfis pessoais a partir de informaçóes coletadas, as liberdade de expressão, a publicação de biografias não autorizadas, o direito ao esquecimento, o direito de não saber, o sigilo fiscal e econômicos, o sigilo processual, o sigilo de dados e comunicações, o segredo empresarial, e, enfim, defender um possível direito à invisibilidade na Sociedade da Informação.

\section{Conclusões}

A presença dos elementos tecnológicos na sociedade, especialmente a Internet, vem transformando o modo dos indivíduos se comunicarem, se relacionarem e construírem conhecimentos. Os bancos de dados e trocas de informaçóes impulsionaram a economia, encurtaram distância e fortificaram as redes científicas e do conhecimento. Como se observa, o cruzamento de dados é a grande preocupação dos defensores da privacidade da pessoa humana, principalmente numa era em que o comércio de informaçóes pessoais identificáveis toma para si a velocidade e impessoalidade na rede.

O debate sobre a garantia e proteção dos dados pessoais tem se tornado cada vez mais pertinente e necessário. A exposição "na internet", o uso de plataformas de redes sociais online, o fornecimento de dados em compras virtuais, têm incomodado aqueles que sentem-se expostos quando conectados. Considerando esta problemática, o presente estudo buscou ancorar sua contextualização na trajetória história da Sociedade da Informação,

10 Dentre as mais significativas conquistas da sociedade ocidental foram os seus direitos individuais, que transformaram sobremaneira o convívio em sociedade, entre esse direitos individuais, esta o direito a um espaço privativo do cidadáo. A necessidade de se proteger a vida privada surgiu da conflitante relaçáo entre o indivíduo e a sociedade. 
tendo como preocupação elencar ideias que visam construir, de forma colaborativa, uma reflexão sobre a proteção aos dados pessoais resguardando o direito a privacidade - desde o cidadão comum que se utiliza da rede apenas como forma de entretenimento até os homens que movimentam a economia ou constroem conhecimento por meio da premissa científica.

\section{Referências}

ALEXY, Robert. Teoria dos direitos fundamentais. Tradução: Virgílio Afonso da Silva. São Paulo: Malheiros, 2012.

BAUDRILLARD, J. A sociedade de consumo. Lisboa: Ediçóes 70, 1975.

BAUMAN, Zygmunt. Vida para consumo (A transformação das pessoas em mercadoria). Tradução Carlos Alberto Medeiros. Rio de Janeiro: ZAHAR, 2008.

. A Modernidade Líquida. Rio de Janeiro: Jorge Zahar, 2001.

. Identidade: entrevista a Benedetto Vecchi. Rio de Janeiro: Zahar, 2005.

. Vida a crédito: conversas com Citali Rovirosa-Madrazo. Rio de Janeiro: Jorge Zahar, 2010.

BOBBIO, Norberto. A era dos direitos. Tradução de Carlos Nelson Coutinho. Rio de Janeiro: Elsevier, 2004.

CANOTILHO, J. Estado de Direito. Cadernos Democráticos no 7, Fundação Mário Soares. Lisboa: Gradiva, 1998.

CASTELLS, Manuel. A sociedade em rede. A era da informação: economia, sociedade e cultura. Tradução de Roneide Venâncio Majer. 7 ed. São Paulo: Paz e Terra, 2003.

CAPELLARI, E. Tecnologias de informação e possibilidades do século XXI: por uma nova relaçáo do estado com a cidadania. In: ROVER, Aires José (org.). Direito, Sociedade e Informática: limites e perspectivas da vida digital. Florianópolis: Fundação Boiteux, 2000.

DERTOUZOS, M. O Que Será: como o novo mundo da informação transformará nossas vidas. São Paulo: Companhia das Letras, 1997.

DONEDA, Danilo Cesar Maganhoto. Da privacidade à proteçáo de dados pessoais. Rio de Janeiro: Renovar, 2006.

FARIAS, Edilson Pereira de. Liberdade de expressão e comunicação. São Paulo: Revista dos Tribunais, 2004.

. Colisáo de direitos: a honra, a intimidade, a vida privada e a imagem versus a liberdade de expressão e informação. 3 ed. Poro Alegre: Sérgio Antônio Fabris, 2008. 
HADDAD, Fernando. Educação para induzir e democratizar o conhecimento científico. Inclusão Social, 1, 2005.

LEMOS, A. Cibercultura: alguns pontos para compreender a nossa época. In: LEMOS, A.; CUNHA, P. Olhares sobre a cibercultura. Porto Alegre: Sulina, 2003. p. 11-23.

LÉVY, Pierre. Cibercultura. Tradução de Carlos Irineu da Costa. São Paulo: 34, 2009.

. La machine univers: création, cognition et culture informatique. Paris: La Découverte, 1987.

. O que é virtual? São Paulo: Editora 34, 2010.

LUHMANN, N. Sistemas sociales: lineamientos para una teoría general. Traducción de Javier Torres Nafarrate. México: Universidad Iberoamericana, 1998.

. A realidade dos meios de comunicaçáo. Trad. de Ciro Marcondes Filho. São Paulo: Paulus, 2005.

MARCONDES, C. H. \& SAYO, L. F. Documentos digitais e novas formas de cooperação entre sistemas de informação em CeT. Ciência da Informação. Brasília, 2002, 31, 42-54.

MATTELART, Armand. História da Sociedade da Informação. São Paulo: Loyola, 2009.

MCLUHAN, M. Os meios de comunicação como extensóes do homem. 13a ed. São Paulo: Ed. Cultrix, 2003.

MENDES, Gilmar; BRANCO, Paulo Gustavo Gonet. Curso de Direito Constitucional. 7 ed. São Paulo: Saraiva, 2011.

MEYER-PFLUG, Samantha Ribeiro. Liberdade de expressão e discurso do ódio. São Paulo: Revista dos Tribunais, 2009.

PIÇARRA, Nuno. Sobre a repartiçáo de competência no Tribunal de Justiça da Uniáo Europeia. Revista do Ministério Público 133, jan-mar 2013, p 11-74.

RODOTÀ, Stefano. A vida na sociedade da vigilância: a privacidade hoje. Tradução: Danilo Doneda e Luciana Cabral Doneda. Rio de Janeiro: Renovar, 2008.

. Tecnopolitica (La democrazia e le nuove tecnologie dela comunicazione. Roma-Bari: Editori Laterza, 1997.

TAPSCOTT, D.; WILLIAMS, A. Wikinomics: how mass collaboration changes everything. New York: Penguin Group, 2010.

TARGINO, M. G. Comunicação científica: uma revisão de seus elementos básicos. Revista Informação \& Sociedade: Estudos. João Pessoa, 2000, p. 10. 
TEIXEIRA, M. Cyberculture: from Plato to the virtual universe. The architecture of collective intelligence. Munique: Grin Verlag, 2012a.

. As faces da comunicação. Munique: Grin Verlag, 2012b.

TÜRCKE, C. Sociedade Excitada: filosofia da sensação. Campinas: Editora Unicamp, 2010.

TOFFLER, Alvin. A terceira onda. 23 ed. São Paulo: Record, 1998.

UNIÃO EURPÉIA. Diretiva 2002/58 CE, de 12 de dezembro de 2002. Relativa ao tratamento de dados pessoais e à protecção da privacidade no sector das comunicaçóes electrónicas (Directiva relativa à privacidade e às comunicaçôes electrónicas). Diário Oficial das Comunidades Europeias, Bruxelas, 31 jul. 2002. Disponível em: <http://eur-lex.europa.eu/pt/index.htm>. Acesso em: 07.03.2013.

ZUFFO, J. A. A infoera: o imenso desafio do futuro. São Paulo: Editora Saber, 1997.

WACHOWICZ, M. Os Direitos da Informação na Declaraçáo Universal dos Direitos Humanos. In: WACHOWICZ, M. (coord.). Propriedade Intelectual \& Internet: uma perspectiva integrada à Sociedade da Informação. Curitiba: Juruá Editora, 2002. 